\title{
Child and youth fuel poverty: assessing the known and unknown
}

\author{
Kimberley O'Sullivan*, Lucy Telfar Barnard, Helen Viggers, Philippa \\ Howden-Chapman \\ University of Otago
}

\begin{abstract}
The broad health effects of fuel poverty include both the physiological and psychosocial effects of exposure to adverse indoor temperatures. Fuel poverty poses a greater risk to groups spending more time at home, including older people, people with disabilities or chronic illness, and families with young children. To date, fuel poverty research has focused on the first two of these groups, while few studies have specifically explored the outcomes of fuel poverty for children. Very little fuel poverty research has been undertaken with children or youth living in cold homes. This paper outlines the literature describing the effects of fuel poverty and cold housing on children and young people and presents new statistical analysis supporting the targeting of fuel poverty policy on households with children. We introduce current research investigating the effects of living in, or living at risk of, fuel poverty on children and youth in New Zealand. We argue that proposed changes to the Residential Tenancies Act need to be strengthened and should include current standard insulation, which is proven to be a cost-effective measure in terms of health, particularly the health of children and young people.
\end{abstract}

Keywords: Fuel poverty; energy poverty; energy insecurity; insulation retrofit; children and youth.

\section{Introduction}

Fuel poverty, described as the inability to afford adequate household energy including heating, is estimated to affect one in four New Zealand (NZ) households (HowdenChapman et al., 2012). It is caused by a combination of the energy inefficiency of dwellings and heating appliances, cost of energy, and income poverty (Clinch and Healy, 1999; Boardman, 1991). Particularly in NZ, where households commonly rely on relatively inefficient plug-in electric heating, and building thermal quality is relatively poor, the cost of electricity is an important driver of fuel poverty. While recognised in other countries, in NZ fuel poverty is not officially defined, measured, or explicitly targeted and its crucial effect on children is largely unrecognised (Howden-Chapman et al., 2012; Howden-Chapman et al., 2009; O'Sullivan et al., 2011; O'Sullivan et al., 2013a; McChesney, 2012; Thomson and Snell, 2013). There has been recent pressure 
on the Government to address child poverty and continued research has highlighted the effects of housing on children's health (Kelly et al., 2013; Howden-Chapman et al., 2013; Children's Commissioner's Expert Advisory Group on Solutions to Child Poverty, 2012). A well-publicised Coroner's Report on the death of a toddler that for the first time identified the substandard condition of the dwelling as a contributing factor created considerable media interest and political responses (Howden-Chapman et al., 2015; Shortland, 2015).

Typical coping strategies of fuel-poor households fall into three broad categories: self-rationing of energy consumption; financial redistribution through restricting other spending; and sometimes debt or disconnection from energy or other services (Gibbons and Singler, 2008; Brunner et al., 2012; Anderson et al., 2012; O'Neill et al., 2006; Harrison and Popke, 2011; Harrington et al., 2005; Gilbertson et al., 2006; Lomax and Wedderburn, 2009). The broad health effects of fuel poverty include both physiological and psychosocial effects of exposure to adverse indoor temperatures (Liddell and Morris, 2010; Marmot Review Team, 2011; Hills, 2012). While research confirms that fuel poverty poses a greater risk to groups spending more time at home, including older people, people with disabilities or chronic illness, and families with young children, few studies have specifically explored the outcomes of fuel poverty for children and youth (Liddell, 2008; Children in Wales, 2011). Negative outcomes of cold indoor temperatures and fuel poverty for children include: reduced calorific intake in winter (Bhattacharya et al., 2003); increased risk of under-nutrition, being overweight, or acute hospitalisation (Frank et al., 2006); poorer health and development outcomes for children under three years (Cook et al., 2008); and the risk of mental health problems and increased antisocial behavior among adolescents (Liddell and Morris, 2010).

NZ research relating to fuel poverty among children is limited, though the available local evidence suggests that fuel poverty is a significant problem for children in the community. Households with children have high rates of social and material deprivation with around 25 per cent or 270,000 children living in poverty, and based on this, are likely to experience fuel poverty (McChesney, 2012; McChesney, 2013; Perry, 2012; Children's Commissioner's Expert Advisory Group on Solutions to Child Poverty, 2012). In a qualitative study about their experiences of living in low socio-economic communities in NZ, children and youth discussed families being unable to afford to pay for electricity, heating, or hot water, and the flow on effects of this on health (EganBitran, 2012). Data from the General Social Survey found that among households with children, 22 per cent reported a major problem with keeping the house warm in winter, and 17 per cent reported major damp or mould problems (Perry, 2009). Another study, Growing up in New Zealand, found that among households with a baby 9 months old, 18 per cent put up with feeling cold to save on heating, 11 per cent used no household heating, and 22 per cent of the babies had heavy condensation in their bedrooms quite often, always, or almost always (Morton et al., 2012).

Prepayment metering is used by three per cent of households, and those with children (54 per cent) are more likely to report restricting grocery spending and financial hardship (O'Sullivan et al., 2013a, O'Sullivan et al., 2013b). A study of children aged under 15 admitted to Wellington Hospital found that 52 per cent lived in housing colder than their parents would like, 14.2 per cent of households had been unable to pay their electricity bills on time and 7.5 per cent had experienced disconnection due to late or non-payment of bills (around four times the national rate) (Kelly et al., 2013). An analysis of hospital admissions for asthma found that they were correlated to electricity prices, especially for young children (Webb and Menclova, 2013). The Heating and Housing study found that increasing home temperatures of children with asthma reduces symptoms and days off school (Howden-Chapman et al., 2008; Free et al., 2010). 
This paper now turns to evidence from current statistics investigating the effects of living in cold indoor environments or fuel poverty on children and youth in NZ. We introduce our ongoing research into the same and conclude by discussing the policy implications of the evidence to date.

\section{New evidence: What can current statistics tell us about home environments for New Zealand children?}

\section{Census: Comparison of heating between households with and without dependent children}

New Zealand's climate and low building quality and standards combine so that almost every home requires heating in winter to achieve thermal comfort (often even new build dwellings). Although there are no national statistics on fuel poverty, we do have census data on heating fuel use.

The 2013 Census indicated that of the 1.5 million households in NZ, 33.2 per cent include dependent children. Households with dependent children had very similar rates of reporting not using heating as households without children (2.9 per cent vs 2.8 per cent). However this similarity masks substantial differences by household type: Table 1 shows the percentage of households of different types which reported using no heating. Overall 33.6 per cent of households that used no heating had dependent children. ${ }^{1}$

Table 1: Households reporting using no heating

\begin{tabular}{lll}
\hline & With dependent children & $\begin{array}{l}\text { With no known dependent } \\
\text { children }\end{array}$ \\
\hline $\begin{array}{l}\text { Couple (either alone or with } \\
\text { others) }\end{array}$ & $2.0 \%$ & $1.9 \%$ \\
$\begin{array}{l}\text { Solo parent (either alone or } \\
\text { with others) }\end{array}$ & $4.6 \%$ & $3.4 \%$ \\
$\begin{array}{l}\text { Two family household } \\
\text { Three+ family household }\end{array}$ & $5.8 \%$ & $4.5 \%$ \\
\hline
\end{tabular}

Data from Statistics New Zealand

Electricity is NZ's most widely used heating fuel (used by 79.2 per cent of households in 2013). The second most common fuel is wood (36.8 per cent) and gas is both third and fourth most common (15.4 per cent bottled and 12 per cent mains).

In addition to households that do not heat at all, we expect households using bottled gas for heating to be at risk of fuel poverty. This is because, in NZ, unflued bottled gas burners are relatively cheap, moveable, and allow the householder to buy their fuel in advance (reducing the risk of unexpectedly high electricity bills or "bill shock"). Bottled gas heating has declined in popularity in recent years (from 28.3 per cent in 2001 to 15.4 per cent in 2013), perhaps because of education campaigns around the effects of the gas combustion products on people's (and especially children's) health. Household types reporting higher rates of non-heating also reported increased rates of bottled gas heating. 
p. 80. Child and youth fuel poverty: assessing the known and unknown

Table 2: Households reporting using bottled gas heating

\begin{tabular}{lll}
\hline & With dependent children & $\begin{array}{l}\text { With no known dependent } \\
\text { children }\end{array}$ \\
\hline $\begin{array}{l}\text { Couple (either alone or with } \\
\text { others) }\end{array}$ & $14.8 \%$ & $16.2 \%$ \\
$\begin{array}{l}\text { Solo parent (either alone or } \\
\text { with others) }\end{array}$ & $17.2 \%$ & $17.9 \%$ \\
$\begin{array}{l}\text { Two family household } \\
\text { Three+ family household }\end{array}$ & $21.2 \%$ & $20.1 \%$ \\
\hline
\end{tabular}

Data from Statistics New Zealand

Warm Up New Zealand (WUNZ) Evaluation Sub-analysis: Child hospitalisation rates

Between July 2009 and March 2010 the NZ government subsidised the retrofitting of a range of energy efficiency options, including ceiling and underfloor insulation, and energy efficient heating, into 46,655 NZ homes. The overall evaluation of this scheme, completed in 2012, showed a significant cost benefit of retrofitting insulation and heating (Telfar Barnard et al., 2012; Telfar Barnard et al., 2015). A new sub-analysis of an evaluation of the Warm Up New Zealand: Heat Smart subsidy programme's effects on child health is presented here.

For the sub-analysis, in order to measure one aspect of the effect of fuel poverty on the health of children, we measured the effect of participation in the WUNZ retrofit scheme on hospitalisation rates in children aged under 15 years, compared to rates for children in control households matched from administrative housing and national health index datasets by Census area unit and housing characteristics. Further details of the matching criteria are described in Telfar Barnard et al. (2012). Data collected for the scheme allowed us to also measure the effect of the scheme on hospitalisation rates among children at particular risk of living in a fuel-poor household, i.e. children in households where one or more members of the household carried a community service card (CSC), and children in households in rental tenure. CSCs are available to NZ citizens or permanent residents, aged 18 years and older, on low to middle incomes. Those receiving social welfare benefits are automatically issued with a card. CSCs allow holders access to lower cost health care, subsidised health services and prescriptions. These data were available at household level for WUNZ treatment households, but not known for control households. Instead, control households were assigned the same CSC and tenure status as their matched treatment household.

Before retrofitting dates, children in treatment households had a raw hospitalisation rate of 760 hospitalisations per 10,000 children per year, while children in control households had 699 hospitalisations per 10,000 children per year. After retrofitting dates, these rates changed to 677 and 670 respectively.

After/before: treatment/control relative rate ratios for all children, and sub-groups are provided in Table 3. 
p. 81. Child and youth fuel poverty: assessing the known and unknown

Table 3: Hospitalisation rates for children after WUNZ retrofit

\begin{tabular}{lll}
\hline Group & RRR & $95 \% \mathrm{Cl}, \mathrm{p}$-value \\
\hline $\begin{array}{l}\text { All children } \\
\text { Sub-group: }\end{array}$ & 0.94 & $(0.88-1.00, \mathrm{p}=0.47)$ \\
Low income households & 0.88 & $(0.81-0.94, \mathrm{p}=0.001)$ \\
Rental tenure & 0.81 & $(0.70-0.93, \mathrm{p}=0.003)$ \\
$\begin{array}{l}\text { High deprivation neighbourhood } \\
\text { (NZDep 9-10) }\end{array}$ & 0.95 & $(0.84-1.07, \mathrm{p}=0.376)$ \\
\hline
\end{tabular}

Participation in the WUNZ scheme reduced total hospitalisation rates for all children by six per cent. Rates for low-income households were reduced by 12 per cent, and for rentals, 19 per cent. These effects were all statistically significant. The effect on total hospitalisations for children in households in areas of high deprivation was not statistically significant.

There were some important potential sources of bias in these results. The overall matching method has a broad bias towards the null (Telfar Barnard et al., 2015). For this specific analysis, it is not known whether households with hospitalised children would have been more or less likely to seek WUNZ retrofits, so there is potential for treatment bias in the results, though the direction of the potential bias is unclear. Also, there may be numerator/denominator information bias towards the null, since we knew the CSC and tenure status of the treatment households, but not the control households.

Nevertheless, as we assess the balance of these biases to have been towards the null, this further evaluation of the WUNZ scheme indicates that energy efficiency retrofits had a positive effect on child hospitalisation rates. We conclude that the effect was greater for children in households at greater risk of fuel poverty.

\section{Ongoing research: Improving home environments for NZ children}

Current research being conducted by He Kainga Oranga/Housing and Health Research Programme and funded by the New Zealand Health Research Council is focused on improving housing for children, with the aim of addressing the identified knowledge gap in relation to children through two new community trials, which are just beginning. In the study A healthy nest is best (NEST): The effects of bedding, insulation and heating on infant respiratory health, researchers will make contact with 600 women in their last trimester of pregnancy and ensure that their home is insulated, and the room in which the baby will be sleeping is heated and has appropriate bedding. In the Safe Housing Enabling Long Term Effective Recovery (SHELTER) study, the homes of children who have been admitted to hospital with respiratory symptoms will have insulation and heating retrofitted and have 'wrap-around' social services.

An innovative collaborative study is also underway, with most of the data collection complete as the first year in the two-year study draws to a close. Cool? Exploring the insights and experiences of New Zealand youth living in, or at risk of, fuel poverty, seeks to explore the experiences of youth living in, or at risk of, fuel poverty using childcentred, participatory research approaches and a multiphase mixed methods research design. 
To date, very little fuel poverty research has been undertaken with children living in cold homes (Children in Wales, 2011; Gibbons and Singler; 2008, Liddell; 2008). A Welsh qualitative study that used informative and participatory workshops with children is a rare exception (Children in Wales, 2011). However, local innovative methodological designs privileging children's knowledge finds them capable, willing, research collaborators (Oliver et al., 2011; Ergler, 2011). Five stages of community-based participatory research processes are described by Israel and colleagues and include : a) research advisory groups informing the study b) identifying priorities, goals, and research questions; c) designing and conducting the research; d) analysing and summarising data and/or interpreting findings; and e) disseminating and translating the research (Israel et al., 2005; Israel et al., 2012).

To achieve collaboration across all five of these stages, three sets of workshops were held in one school over the course of 2015. The school ranked towards the lower end of the Ministry of Education's decile rating system, which indicates the proportion of students from low socio-economic communities in each school - the Decile 2 school was in the 10-20 per cent bracket of schools with the highest proportion of students from low socio-economic communities. ${ }^{2}$

Workshops included: 1) discussion of the research process and topic of fuel poverty, extending invitation to youth to participate in a research collaboration group at their chosen level of involvement (McCarry, 2011), and development of a questionnaire for a nationwide online survey of youth from other schools; 2) analysis of initial data from the survey, discussion of results, and development of the interview schedule for email-interviews with young people who consented to follow-up at the end of the online survey. Some young researchers were given basic training in interviewing techniques and ongoing supervision to undertake peer-to-peer interviews (data collection continues) (Alderson, 2001; Schäfer and Yarwood, 2008). 3) After preliminary data analysis of interviews the results, conclusions and recommendations of the research was discussed. A seminar was held where youth researchers presented initial findings to key stakeholders, which was very well received. Academic papers are currently being collaboratively drafted for submission (Jacquez et al., 2013).

To date, the workshops and survey have been completed. At the beginning of the first workshop session, the young researchers indicated that they preferred the maximum level of involvement in the research process possible. Anonymous feedback from the young researchers during a process evaluation of the early stages of this work found that the youth researchers were overall very positive about their involvement in the research process, and of the process itself. The process of allowing for meaningful collaboration has contributed in part to the length of the study and the workshop sessions, where a more streamlined approach would have been preferable to the young researchers. Where possible we have condensed the study phases so that data collection and initial analysis is planned for completion within the school year, enabling young researchers involvement throughout the process right through to dissemination. This leaves integrative analysis of the discrete phases in this mixed methods research for the second year of the study.

Preliminary statistical analysis of initial data, undertaken with the youth researchers during the second set of workshops, indicates support for the hypothesis underlying the study, that cold housing is problematic for young people. Initial qualitative analysis of open-answer responses from the survey and e-interviews (data collection for which are ongoing) also support the hypothesis. A clear early finding is that young New Zealanders see cold housing as an important issue affecting their health and wellbeing, and that they would like to see further government action to improve indoor environments for young people. The overall research design to date is yielding both rich 
and valid data on youth experiences of cold housing and achieving true participation of the youth researchers, providing as much equality with adult researchers as possible.

\section{Discussion and conclusions}

Accumulating evidence raises the concern that fuel poverty has important negative effects for children and young people, who have been under-represented in research investigating fuel poverty to date. Increasingly, research specifically focuses on the physical health outcomes for children living in conditions associated with fuel poverty including cold indoor temperatures, damp, and mould. However, little research has explored children and youth experiences of fuel poverty, and even less research has prioritised their participation in the research process. In this article we have outlined ongoing research being undertaken by He Kainga Oranga/Housing and Health Research Programme in NZ to address this research need. However, our new analysis of available statistics support immediate policy action to reduce the risk of insufficiently warm home environments that many NZ children are currently exposed to.

Census data show that one third of households reporting using no heating have dependent children. Use of unflued gas heating is most common in multi-family households with dependent children. Both non-heating and use of unflued gas heating are important fuel poverty indicators in NZ. Evaluation of the WUNZ retrofitting programme finds that the scheme reduced total hospitalisations for all children by six per cent. Importantly for policy targeting, hospitalisations for children in households with CSCs, an indicator of low income, were reduced by 12 per cent, and for children in rental housing hospitalisations were reduced by a substantial 19 per cent. These results have important implications for future retrofitting policies.

The Government has recently announced minimum standards for all rental housing. While we welcome the inclusion of these standards to all rental housing, these proposed changes to the Residential Tenancies Act (RTA) will require landlords only to fit a smoke detector, and to ensure rental properties are insulated. Wall insulation is not required, underfloor insulation must be in "reasonable condition". Ceiling insulation required must be only $70 \mathrm{~mm}$ thick, the level equivalent to the 1978 standard, as opposed to the current building standards set in 2008. The standards are to be phased in between 2016 and 2019 (Smith, 2015). Other changes aim to enable faster resolution of tenancy abandonment cases; and strengthen the enforcement power of the RTA. The minimum standards set are not supported by research evidence showing that a comprehensive Warrant of Fitness for rental housing, as developed over a decade by He Kainga Oranga/Housing and Health Research Programme, would improve public health and is largely acceptable and without significant cost to landlords (Bennett et al., Accepted with Revisions). It is unclear why the Minister selected the 1978 ceiling insulation standard, just over half the thickness of that of the successful and cost-effective WUNZ scheme $(70 \mathrm{~mm}$ vs $120 \mathrm{~mm})$. His comments on announcing the proposed changes suggest he weighted limiting cost over the negative health and social effects of the poor quality residential building stock: "This pragmatic package of tenancy law changes will make homes warmer, drier and safer for hundreds of thousands of New Zealand families without imposing excessive bureaucracy or cost."3

We recommend that the proposed changes to the RTA be strengthened to include current-standard insulation, proven to be a cost-effective measure to improve health, and particularly child health. Concerns over public spending could be managed by additional policy phasing for properties built between 1978 and 2008, thereby exempting dwellings built after the first insulation standards were required from reaching the 2008 standard, rather than by requiring all dwellings to only reach the 
1978 standard. We continue to support the introduction of a comprehensive Warrant of Fitness for residential buildings. In the absence of a definition of fuel poverty and a method for measurement among NZ households, we suggest the most effective and strategic targeting of remedial policies, such as the WUNZ scheme, would be to prioritise rental households with children, where the most urgent need and largest health-gains have been identified without delay.

We anticipate further evidence supporting the prioritisation of households with children in public policy improving indoor environments to arise from our ongoing programme of research. We also highlight the clear initial findings from the Cool? study undertaken with our young research collaborators that young New Zealanders see inadequate home environments as an important issue which requires Government attention.

\section{Notes}

1) This work is based on/includes customised Statistics New Zealand's data which are licensed by Statistics New Zealand for re-use under the Creative Commons Attribution 3.0 New Zealand license.

2) http://www.education.govt.nz/school/running-a-school/resourcing/funding-staffingand-allowances-handbook/chapter-1-operational-funding/decile-ratings/

3) https://www.beehive.govt.nz/release/tenancy-law-changes-include-insulation-andsmoke-alarm-requirements

\section{Acknowledgements}

We would like to acknowledge the work of Waiopehu College's 10W 2015 Research Team on the Cool? Study. The first author was supported by a grant from the Lotteries Health Research Committee (Grant Application \#352235) while undertaking this work. All authors are researchers in the He Kainga Oranga/Housing and Health Research Programme, University of Otago, Wellington, and funded by the Health Research Council.

* Correspondence address: Dr Kimberley O'Sullivan, He Kainga Oranga/Housing and Health Research Programme, Department of Public Health, University of Otago Wellington, PO Box 7343, Wellington South 6242, New Zealand. Email: kimberley.osullivan@otago.ac.nz

\section{References}

Alderson, P. (2001) Research by children. International Journal of Social Research Methodology, 4, 139-153.

Anderson, W., White, V. and Finney, A. (2012) Coping with low incomes and cold homes. Energy Policy, 49, 40-52.

Bennett, J., Howden-Chapman, P., Chisholm, E., Keall, M., Baker, M.G. and The Rental Housing WOF Team (Accepted with Revisions) Towards an agreed quality standard for rental housing: Development of a New Zealand housing WOF tool. Australian and New Zealand Journal of Public Health. 
p. 85. Child and youth fuel poverty: assessing the known and unknown

Bhattacharya, J., Deleire, T., Haider, S. and Currie, J. (2003) Heat or Eat? Cold-Weather Shocks and Nutrition in Poor American Families. American Journal of Public Health, 93, 1149-1154.

Boardman, B. (1991) Fuel Poverty: From Cold Homes to Affordable Warmth. London: Belhaven Press.

Brunner, K.M., Spitzer, M. and Christanell, A. (2012) Experiencing fuel poverty. Coping strategies of low-income households in Vienna/Austria. Energy Policy, 49, 53-59.

Children in Wales (2011) Keeping warm this winter: Hearing the voices of children and young people in tackling fuel poverty in Wales. Cardiff: Children in Wales, Consumer Focus Wales.

Children's Commissioner's Expert Advisory Group on Solutions to Child Poverty (2012) Solutions to Child Poverty in New Zealand: Evidence for Action. Wellington: Office of the Children's Commissioner.

Clinch, J.P. and Healy, J.D. (1999) Alleviating fuel poverty in Ireland: a program for the 21st century. International Journal for Housing Science, 23, 203-215.

Cook, J.T., Frank, D.A., Casey, P.H., Rose-Jacobs, R., Black, M.M., Chilton, M., Decuba, S.E., Appugliese, D., Coleman, S., Heeren, T., Berkowitz, C. and Cutts, D.B. (2008) A Brief Indicator of Household Energy Security: Associations With Food Security, Child Health, and Child Development in US Infants and Toddlers. Pediatrics, 122, e867-e875.

Egan-Bitran, M. (2012) Our views matter: Children and young people talk about solutions to child poverty - a consultation carried out for the the Children's Commissioner's Expert Advisory Group on Solutions to Child Poverty. Wellington: Office of the Children's Commissioner.

Ergler, C. (2011) Beyond Passive Participation: Children as Collaborators in Understanding Neighbourhood Experience. Graduate Journal of Asia-Pacific Studies, 7, 78-98.

Frank, D.A., Neault, N.B., Skalicky, A., Cook, J. T., Wilson, J.D., Levenson, S., Meyers, A.F., Heeren, T., Cutts, D.B., Casey, P.H., Black, M.M. and Berkowitz, C. (2006) Heat or Eat: The Low Income Home Energy Assistance Program and Nutritional and Health Risks Among Children Less Than 3 Years of Age. Pediatrics, 118, e1293-e1302.

Free, S., Howden-Chapman, P., Pierce, N., Viggers, H. and The Housing Heating and Health Study Team (2010) More Effective Home Heating Reduces School Absences for Children with Asthma. Journal of Epidemiology and Community Health, 64, 379-369.

Gibbons, D. and Singler, R. (2008) Cold comfort: A review of coping strategies employed by households in fuel poverty. London: Centre for Economic and Social Inclusion.

Gilbertson, J., Stevens, M., Stiall, B. and Thorogood, N. (2006) Home is where the hearth is: Grant recipients' views of England's Home Energy Efficiency Scheme (Warm Front). Social Science and Medicine, 63, 946-956.

Harrington, B.E., Heyman, B., Merleau-Ponty, N., Stockton, H., Ritchie, N. and Heyman, A. (2005) Keeping warm and staying well: findings from the qualitative arm of the Warm Homes Project. Health and Social Care in the Community, 13, 259-267.

Harrison, C. and Popke, J. (2011) "Because You Got to Have Heat": The Networked Assemblage of Energy Poverty in Eastern North Carolina. Annals of the Association of American Geographers, 101, 949-961.

Hills, J. (2012) Getting the Measure of Fuel Poverty: Final Report of the Fuel Poverty Review. London: Centre for Analysis of Social Exclusion.

Howden-Chapman, P., Beirre, S. and Baker, M. (2013) The houses children live in: policies to improve housing quality. Policy Quarterly, 9. 
Howden-Chapman, P., O'Sullivan, K., Bierre, S., Chisholm, E., Hamer-Adams, A., Ombler, J. and Amore, K. (2015) What effect will the 2015 Budget have on housing? Policy Quarterly, 11, 13-19.

Howden-Chapman, P., Pierce, N., Nichols, S., Gillespie-Bennett, J., Viggers, H., Cunningham, M., Phipps, R., Boulic, M., Fjallstrom, P., Free, S., Chapman, R., Lloyd, B., Wickens, K., Shields, D., Baker, M., Cunningham, C., Woodward, A., Bullen, C. and Crane, J. (2008) Effects of improved home heating on asthma in community dwelling children: randomised controlled trial. British Medical Journal, 337, 1411-1420.

Israel, B.A., Eng, E., Schulz, A.J. and Parker, E.A. (eds.) (2012) Methods in CommunityBased Participatory Research for Health. San Fransisco, CA: Jossey-Bass.

Israel, B.A., Eng, E., Schulz, A.J., Parker, E.A. and Satcher, D. (eds.) (2005) Methods in Community-Based Participatory Research for Health. San Fransisco, CA: JosseyBass.

Jacquez, F., Vaughn, L. and Wagner, E. (2013) Youth as Partners, Participants or Passive Recipients: A Review of Children and Adolescents in Community-Based Participatory Research (CBPR). American Journal of Community Psychology, 51, 176-189.

Kelly, A., Denning-Kemp, G., Geiringer, K., Abdulhamid, A., Albabtain, A., Beard, M., Brimble, J., Campbell, A., Feng, S., Haminudin, M., Hunter, J., Kunac, N., Lin, P., Lundon, N., Richter, J., Keall, M., Howden-Chapman, P. and Baker, M.G. (2013) Exposure to harmful housing conditions is common in children admitted to Wellington Hospital. New Zealand Medical Journal, 126, 108-126.

Liddell, C. (2008) Policy briefing: The impact of fuel poverty on children. Belfast: Save the Children.

Liddell, C. and Morris, C. (2010) Fuel poverty and human health: A review of recent evidence. Energy Policy, 38, 2987-2997.

Lomax, N. and Wedderburn, F. (2009) Fuel Debt and Fuel Poverty: A Case Study of Financial Exclusion. Dorking: Friends Provident Foundation.

Marmot Review Team (2011) The Health Impacts of Cold Homes and Fuel Poverty. London: Friends of the Earth and the Marmot Review Team.

McCarry, M. (2011) Who benefits? A critical reflection of children and young people's participation in sensitive research. International Journal of Social Research Methodology, 15, 55-68.

McChesney, I. (2012) Fuel poverty in New Zealand - A public policy investigation. Welllington: Victoria University of Wellington.

McChesney, I. (2013) Child Poverty the 'fuel poverty' dimension. Policy Quarterly, 9, 4046.

Morton, S.M.B., Atatoa Carr, P.E., Grant, C.C., Lee, A.C., Bandara, D.K., Mohal, J., Kinloch, J.M., Schmidt, J.M., Hedges, M.R., Ivory, V.C., Kingi, T.R., Laing, R., Perese, L.M., Peterson, E., Pryor, J.E., Reese, E., Robinson, E.M., Waldie, K.E. and Wall, C.R. (2012) Growing Up in New Zealand: A longitudinal study of New Zealand children and their families. Report 2: Now we are born. Auckland.

O'Neill, T., Jinks, C. and Squire, A. (2006) "Heating Is More Important Than Food": Older Women's Perceptions of Fuel Poverty. Journal of Housing for the Elderly, 20, 95108.

O'Sullivan, K.C., Howden-Chapman, P. and Fougere, G. (2011) Making the connection: the relationship between fuel poverty, electricity disconnection and prepayment metering. Energy Policy, 39, 733-741.

O'Sullivan, K.C., Howden-Chapman, P.L., Stanley, J. and Hales, S. (2013a) Kids in the Cold: Outcomes for households with children using prepayment metering for electricity. New Zealand Medical Journal, 126, 71-81.

O'Sullivan, K.C., Howden-Chapman, P.L., Fougere, G.M., Hales, S. and Stanley, J. (2013b) Empowered? Examining self-disconnection in a postal survey of 
electricity prepayment meter consumers in New Zealand. Energy Policy, 52, 277287.

Oliver, M., Witten, K., Kearns, R., Mavoa, S., Badland, H.M., Carroll, P., Drumheller, C., Tavae, N., Asiasiga, L., Jelley, S., Kaiwai, H., Opit, S., Lin, E.-Y. J., Sweetsur, P., Barnes, H. M., Mason, N. and Ergler, C. (2011) Kids in the city study: research design and methodology. BMC Public Health, 11.

Perry, B. (2009) Non-income measures of material wellbeing and hardship: first results from the 2008 New Zealand Living Standards Survey, with international comparisons. In: DEVELOPMENT, M. O. S. (ed.). Wellington.

Perry, B. (2012) Household incomes in New Zealand: Trends in indicators of inequality and hardship 1982 to 2011. Wellington: Ministry of Social Development.

Schäfer, N. and Yarwood, R. (2008) Involving young people as researchers: uncovering multiple power relations among youths. Children's Geographies, 6, 121-135.

Shortland, H.B. (2015) Findings of Coroner H. B. Shortland: An inquiry into the death of Emma-Lita Pepe Quintanella Bourne. Whangarei.

Smith, N. (2015) Insulation, smoke alarms and other residential tenancy improvements. Wellington: Cabinet Social Policy Committee.

Telfar Barnard, L., Preval, N., Howden-Chapman, P., Arnold, R., Young, C., Grimes, A. and Denne, T. (2012) The Impact of Retrofitted Insulation and New Heaters on Health Services Utilisation and Costs, Pharmaceutical Costs and Mortality: Evaluation of Warm Up New Zealand: Heat Smart. Wellington: Ministry of Economic Development.

Telfar Barnard, L.F., Baker, M.G., Hales, S. and Howden-Chapman, P. (2015) Novel use of three administrative datasets to establish a cohort for environmental health research. BMC Public Health, 15, 246.

Thomson, H. and Snell, C. (2013) Quantifying the prevalence of fuel poverty across the European Union. Energy Policy, 52, 563-572.

Webb, R. and Menclova, A. (2013) Home heating and asthma in New Zealand. Christchurch: Department of Economics and Finance, School of Business and Economics, University of Canterbury. 